covers $48^{\circ}$ of Jovian longitude, and its centre will be in conjunction with the centre of the Great Red Spot in June, 1904. Differences of period have been exhibited by three of the most conspicuous spots situated on the red, narrow belt north of the $\mathrm{N}$. equatorial belt, their respective periods being (1) $9 \mathrm{~h} .55 \mathrm{~m} .358 \mathrm{~s}$, , (2) $9 \mathrm{~h} .55 \mathrm{~m} .3 \mathrm{I} \cdot 5 \mathrm{~s}$. , and (3) 9 h. $55 \mathrm{~m} .266 \mathrm{~s}$. Greater differences of rate have been shown in the N. temperate and N.N. temperate spots, one group of six showing a period of $9 \mathrm{~h} .55 \mathrm{~m}$. $57 \mathrm{~s}$., whilst the observed period of another similar group of six was gh. $55 \mathrm{~m}$. 4 os.

Meridian. Circle Observations of Eros and Nova PERSEI.--The results of the Harvard meridian circle observations of Eros and the comparison stars are published in No. 6, vol. xlviii., of the Harvard College Observatory Annals. The comparison stars are those given in Circulaire No. 4 of the Conferrence Astrophotographique Internationale, and were observed over bright wires in a dark field. Tables showing the elements of the reduction of the observed places are given, and are followed by a table showing the position of Eros on six evenings in November and one in December, rgoo.

No. 7 of the same volume of the Harvard College Observatory Annals contains the results of the meridian circle observations of Nova Persei and comparison stars. The observations and reductions were similar in character to those made for Eros-except that Nova Persei was observed in a red field over dark wires-and have been made by the same observer, Mr. John A. Dunne. The final table gives the magnitude, the apparent and mean places, and the 1900 o positions of the Nova, as determined on fourteen dates between February 24, 1901, and January 24, 1902. The observations have all been reduced to Auwers's system of star-places.

Periodical Comets due this Year.-Mr. W. T. Lynn, in a letter to the Observatory (No. 340), gives a short account of the following periodical comets which are due to return to perihelion during this year. Winnecke's comet should become visible in the early part of the year, as it performed its previous perihelion passage on March 20, 1898 , and has a period of about 58 years. Tempel's comet (1873), having a period of about 5.28 years, was observed on its return in 1894 and again in 1899, and in the latter year it passed through perihelion on July 28 . It should therefore return towards the end of the present year.

The now familiar object discovered by Méchain in 1786 and known as Encke's comet has been observed at every return since $1818-19$, and should be visible again during the latter end of this year. The period is about 33 years, and the last perihelion passage took place on September ${ }^{15}$, 190.

\section{RECENT CONFERENCES OF SCIENCE} TEACHERS.

VEAR by year the conferences arranged by the Technical Education Board of the London County Council have increased in importance. This January no less than $85^{\circ}$ teachers attended the meetings-which occupied three whole days, January 7,8 and $9-$ at the South-western Polytechnic. Moreover, a valuable and suggestive exhibition of matters dealing with its special subject, arranged by the Geographical Association, was opened two days before the conferences began, and the collection remained on view until they ended.

Mr. A. J. Shepheard, chairman of the Technical Education Board of the London County Council, presided over the first meeting on January 7 , and gave a very cordial welcome to all present. His opening address dealt with the conclusions which he, as a member of the Mosely Commission, had drawn from his recent visit to the United States of America. By way of introduction $\mathrm{Mr}$. Shepheard very briefly indicated the steps that led up to the inquiries which Mr. Mosely had boldly instituted. The fact that American engineers had succeeded in mining operations when Englishmen had failed raised the question as to whether the success was due to American education. The commission, upon which Mr. Shepheard served, resulted, and it was intended to determine whether there were any points in American education which are superior to our own.

$\mathrm{Mr}$. Shepheard found that in America there was a more largely diffused spirit of education and a greater belief in its necessity and value than here in England. The American people were taught to cherish the idea that they had a right to the best education possible, and at the expense of the State; while the State recognised clearly its duty in this respect, and regarded such work as the best investment that it could make.

Here there is an undoubted lesson to England, and $\mathrm{Mr}$. Shepheard strongly urged all. who believe in education, not to let the matter rest until every citizen feels that this nation will never be what it ought, until everyone is educated to the fullest extent to which he or she is capable. America, Mr. Shepheard went on to say, was fortunately free from "the religious difficulty," and in this country in future, sectarian questions must be strictly kept in the background. Education in America is free up to the age of eighteen years, and the universities are more open than here. The manner of teaching is more practical, and without losing our reputation for culture we might consider this point more. The value placed upon nature-study in the United States was considered by $\mathrm{Mr}$. Shepheard, who dwelt upon observational work, painting from nature, weather notes, and the consideration of all natural objects of interest. Finally, Mr. Shepheard discussed manual training, the trade high schools, and the career of a student in such institutions as the Boston Technical School and the universities.

$\mathrm{Mr}$. H. J. Mackinder, reader in geography to the University of Oxford, contributed the first paper, entitled "The Development of Geographical Teaching out of NatureStudy." He digressed for a moment to point out that there was no great antithesis between culture and practical education. We are creatures of history, and we have chosen different methods of cultivating imagination from those adopted by the Americans. Geography, he said, was calculated to expand the imagination, and should start with the home. He quoted the paragraph on the scope of naturestudy from the judges' report of the exhibition held in 1902 , and proceeded to show that geography, as now understood, followed many of the same paths. Mr. Mackinder sketched out some excellent methods of teaching geography, beginning with the construction of a rough plan, and discussed the use of globes and maps without lettering before dealing with such as are commonly used, and which, as he says, tend to dwarf the imagination. He had something also to say about the far-reaching commercial importance of geography, and all right thinking people will support his plea that the idea be at once stamped out which implies that the British possessions can be studied apart from the world as a whole.

At the afternoon meeting Sir John Cockburn in a telling manner summarised from the chair the various matters at issue, Mr. Kendall, of the Yorkshire College, Leeds, described some ingenious methods of filling in the steps of models (made up of thicknesses of cardboard cut according to contour lines) with dry material, which is set by having water sprayed upon it.

$\mathrm{Mr}$. J. Lomas, when treating of excursions, gave a description of a ramble along the banks of a tiny stream in Cheshire. He showed with the help of some specially prepared lantern slides, the questions which it, in common with latger rivers, asks and-yielding to the careful observations of the nature student-likewise answers. Why is here a waterfall? Why is there a patch of sand? The fact that the stream is small is a great help in determining what has altered and is altering its course, and in making experiments to determine the direction of various currents. Mr. Lomas concludes that the object of teaching should be to see that the pupil receives correct impressions, and the only way, he says, to secure this is by observation.

Dr. A. J. Herbertson showed by means of a lantern a number of Ordnance maps illustrating typical regions, and considered the points that go to make a gcod map. He alluded also to the issue of Ordnance Survey maps to schools for teaching purposes (owing to recommendations of the Geographical Association) at a cost of $25 \mathrm{~s}$. per hundred for outlines and $35 \mathrm{~s}$. for the same number when hill-shading is added.

Mr. T. Alford Smith gave an account of the use of simple

NO. I 786 , voL. 69] 
globes in his class, and showed how a lantern may be used with them to explain the production of night and day. The meetings on Friday, January 8 , and on the morning of January 9 were devoted to questions connected with the teaching of languages and art. At the concluding meeting Mr. W. Hibbert described some new forms of apparatus; the most important of these was a magnetic balance devised by him, which has a very long magnetometer needle, and permits the direct estimation of magnetic forces in dynes. Afterwards Prof. Perry, who took the chair, briefly summarised his ideas on the practical teaching of mathematics, and a discussion took place which was introduced by Mr. R. W. Bayliss, of St. Dunstan's College, Catford, who read the paper on practical work in the teaching of geometry. Among the speakers were Mr. Eggar, of Eton, Mr. Garstang, of Bedales, Mr. Harrison, and $\mathrm{Mr}$. Jackson. The general opinion was in favour of making the teaching of geometry practical, but the importance of not forgetting the mental side of the question was emphasised by some speakers.

The geographical exhibition will be shown in other parts of the country, and should prove of very great use to teachers. Individual exhibits which call for attention are the half-inch to a mile reduced survey map of England and Wales without black printing, exhibited by the London School of Economics and issued by Messrs. J. Bartholomew and Co.; the model of the Alps, exhibited by Prof. Dinges the tinted Siegfried map of Switzerland (one in fifty thousand), brought by Dr. Herbertson to illustrate his remarks, and the excellent maps, geological and topographical, prepared by the Japanese Survey. The number of exhibits officially sent by various Government departments shows the interest taken in the matter. Of the numerous other matters we can only allude to Mr. Freshfield's photographs illustrating types of scenery and to Captain WilsonBarker's pictures of clouds.

Prof. Tilden, president of the Association of Public School Science Masters, took the chair at the annual meeting held on January 16 at Westminster School, by kind permission of Dr. Gow. The chairman alluded to the influence exerted during the last year upon educational authorities by the Association, and prophesied that its voice would be heard with still greater effect in the future. He pointed out that a' attempt was being made to stifle chemistry in the examinations for medicine, and that the exigencies of time prevented engineering students from obtaining the physical knowledge that they ought to have. The solution of the difficulty Prof. Tilden thought would be found in the preparation at school of boys intended for such professions and in their being required to show evidence of the fact before entering upon their special studies.

After the election of Sir Michael Foster as president for the year 1905, and the filling up of vacancies upon the executive committee, the meeting proceeded to discuss the possibility of coordinating the teaching of mathematics and science in public schools. The subject was brought forward by Mr. R. E. Thwaites (Malvern), who pointed out that it would be of the greatest help to public school science if a thorough sympathy and understanding were established between mathematical and science masters. As means to this end it was suggested that practical mensuration should $\mathrm{b} \geq$ extended and taught by mathematical men-if possiblein the physics laboratory. Secondly, practical mathematics should be taught to all boys who take theoretical mechanics at present, and this should also be undertaken by the mathematical staff. The fact that mathematical men are regarding the practical bearings of their subject with increased favour was adduced as evidence of the possibility of such hopes being realised. Moreover, the Army Com. mittee has decided that candidates must take a course of practical measurements as part of their mathematics. This can only be carried out properly in the physics laboratory. In view of mathematical men taking laboratory classes a course of practical physics ought to be made obligatory on candidates for honours degrees in mathematics.

Mr. C. S. Jackson (Woolwich), speaking at the beginning of the discussion that followed, said that the reforms should not be put off, as he did not think mathematical men needed a special training, as shown by the introduction of models into their teaching of solid geometry.

Mr. W. D. Eggar (Eton) supported Mr. Thwaites's conNo. I 786, vor. 69] tentions, and suggested that mathematical masters who went into the laboratory would find no difficulty in keeping a page or two ahead of their boys, while they would learn much of great value to themselves. He condemned the study of electricity and optics, without reference to laboratory work, for university examinations, and, turning to another aspect of public school work, thought that classical masters might help in the pursuit of nature-study.

Mr. W. C. Fletcher (Board of Education) pointed out that the reforms hoped for by his audience he had seen carried out, for in the school at Liverpool of which he was recently head the mathematical masters took their share in the physics teaching, which gave them a fresh interest in their work. He thought that at first the teaching of physics and of mathematics should be in the hands of the same man.

Other speakers on the subject were:-Mr. W. E. Cross (Felsted), Mr. A. W. Siddons (Harrow), Mr. W. A. Shenstone, F.R.S. (Clifton), and Mr. H. Clissold (Clifton).

Mr. M. D. Hill (Eton) started a discussion upon the examination for the Oxford and Cambridge higher certificate. He considered only the position of biology, the teaching of which in public schools would not be encouraged by the examination question, in which its position was unsatisfactory from the point of view of both teacher and pupil. For instance, only one of the six branches could be offered by the candidates, and since practical work is not required, knowledge gained from books rather than from nature would result, and successful papers be written by a candidate who had never seen the objects which he described. HI claimed, further, that biology should be placed on an equal footing with other sciences in which public school boys are examined.

Mr. W. A. Shenstone, F.R.S., spoke of the disadvantages of having no practical work in the physics of the same ex amination. He thought also that the chemistry syllabus was overloaded, and that no line ought to be drawn between organic and inorganic chemistry. Finally, he proposed a resolution to the effect that the opinion of the members of the Association should be taken upon the syllabus, and that the committee, if necessary, should approach the examining board in connection with it. After some discussion the motion was unanimously passed.

The last paper, on "Nature-Study," was read by Mr. O. H. Latter (Charterhouse); he characterised the scope of nature-study as being very wide, and mentioned a host of sciences which, strictly speaking, took cognisance of the material made use of. In fact, he said that nature-study included nearly all visible phenomena. Its object, he continued, is to train the eye to see appreciatively, to awaken interest and to foster certain valuable habits. The matter must be determined by the season of the year and the situation of the school, and an orderly sequence of lessons is not essential. Mr. Latter pointed out how useful the knowledge obtained may be made when English composition is being undertaken. The boy in ordinary cases is gravelled for lack of matter, but when he has observed for himself he is able to put down what he has learned in a way that is interesting and shows individuality. Though he made no attack upon physics and chemistry, which had their own and necessary uses in education, Mr. Latter said that in many respects nature-study is superior to them, especially for young children, and the training which it affords is different in kind. The habits acquired are of value in all walks of life, but they would be especially so in a military service, and Mr. Latter much regretted that what he terms "field subjects" were entirely absent from army examinations. Nature-study, in Mr: Latter's opinion, has come to stay, and will, before long, take a regular place in the early stages of our education. One of the greatest faults of our school system is that the desire for knowledge on the part of the child-who is by nature both: inquisitive and observant-is killed outright in most cases by the time that the age of seventeen is reached. It was suggested that nature-study might profitably be employed in the two or three lowest forms of our public schools, but as it is of specially great importance in preparatory schools, $\mathrm{Mr}$. Latter thought that the Association"should approach the preparatory school masters with a view to obtaining some uniformity of action on their part. The matter is particularly urgent, as a combined examination for entrance 
to a number of public schools is likely to be devised in the future. In conclusion, Mr. Latter was of opinion that nature-study might with advantage be extended to advanced biological work of the school and university laboratories.

A discussion followed, in which the chairman, Mr. Hill, Mr. Shenstone, Mr. Talbot and others took part. Prof. Armstrong said that the phrase " nature-study " was simply a "war cry" at present, and was being used by one party for something which was scientific neither in its intentions nor methods. Later on in the discussion the facts were mentioned that nature-study has a general educational significance, and is recognised in England as expressing the methods of science, but as being otherwise of an informal character.

In reply, Mr. Latter said that all he wanted was that the boys should have their eyes opened, and a resolution was passed that a subcommittee should be appointed to communicate with the preparatory schools in order to determine the form of science teaching best suited to their needs.

Wilfred Mark WebB.

\section{THE ORIGIN OF THE AUSTRALIAN MARSUPIALS.}

THE relationships of marsupials in general to other mammals, the route by which their Australasian representatives reached their present habitat, and the date of their arrival, are problems which have of late years attracted a large amount of attention on the part of naturalists, and are still far from being definitely solved. $A$ bold and vigorous attempt to determine these questions has lately been made by a promising young Canadian zoologist, Dr. B. A. Bensley, of Toronto University; who a few years ago paid a visit to England for the purpose of studying the unrivalled amount of material in the British Museum. The final results of his investigations have just been published in the Transactions of the Linnean Society of London. Needless to say, this elaborate memoir is bristling with technicalities, and much of its contents is of far too abstruse a nature to be even touched upon in a journal like our own. Nevertheless, there are certain parts of more general interest which admit of notice.

One of the difficulties which beset the study of the group has arisen from the discovery, by an Australian naturalist, that the bandicoots, unlike other marsupials, possess vestiges of a placenta, by means of which the maternal blood is brought into direct connection with that of the fœetus, and the question is whether this implies a much nearer relationship between marsupials and ordinary placental mammals than has been generally supposed to exist. Dr. Bensley answers the question in the negative, believing the bandicoot placenta to have had an independent origin. He may, of course, be right in this surmise, but it must always be remembered, as in analogous cases, that this is a summary, if convenient, way of getting rid of difficulties. Even, however, on this view, the author is of opinion that the relationship between marsupials and placentals is much more intimate than was believed to be the case by the older naturalists.

As the result of the investigations of several modern naturalists, the belief is gradually gaining ground that all the modern marsupials, with the possible exception of the Tasmanian wolf, or thylacine, are derived from a primitive arboreal type, of which the South American opossums (not the animals so miscalled in Australia) are now the only representatives. This arboreal ancestry is chiefly displayed in the structure of the foot, and even the essentially terrestrial kangaroos can be easily traced, through the phalangers (the miscalled opossums of Australia), into connection with an arboreal type. Somewhat curiously, it may be mentioned in passing, certain members of the former group - to wit, the tree-kangaroos-show a kind of reversion to the arboreal life of their ancestors. There are, however (as, indeed, would be manifestly impossible), no signs of reversion to the original grasping type of foot, tree-kangaroos hopping on the larger branches in the characteristic manner.

The opossums, then, are the most primitive of living No I786, voL. 69] marsupials, and since they date from the earlier portion (Eocene) of the Tertiary period, they are likewise the earliest animals which can be definitely included in that group, for there is great doubt whether any of the small mammals of the Secondary epoch (those, for instance, of the Stonesfield slate and Purbeck beds) are really marsupials, or at all events marsupials as we now know them.

The arboreal "radiation" (to use a term now extensively employed by American zoologists) of marsupials differentiates them from the extinct creodonts, or primitive Carnivora, of the early Tertiary epoch, which appear to have been essentially terrestrial types. Nevertheless, by means of certain Middle Tertiary South American forms (the so-called sparassodonts), these same creodonts appear to have been very closely connected with the thylacine, and thus with other marsupials, and this presumed relationship seems to have considerably puzzled Dr. Bensley. For, while including that animal in the Dasyuridæ, he suggests that it may be an altogether foreign member of the Australian fauna, and that its origin may have to be sought elsewhere-presumably in South America. He adds that no signs of arboreal ancestry are to be detected in the thylacine's foot. If this means anything, it seems to imply that the animal in question is not related at all to the typical arboreal marsupials, but that its kinship (unless the resemblances are due to " parallelism in development") is with the South American sparassodonts, and thus with the creodonts. But if so, it surely seems to follow that the creature is not, phylogenetically, a marsupial at all. The whole question seems a hopeless puzzle, and if the author cannot explain it, most surely we will not make the attempt.

To turn to less debatable ground, great interest attaches to the author's remarks concerning the huge extinct marsupial from Australia described by Owen as a carnivore, under the name of Thylacoleo. Arguing from the resemblance of its dentition to that of the phalangers, later writers, however, came to the conclusion that the creature was herbivorous. This view is discredited by Dr. Bensley, who, following Dr. Broom, reverts to the opinion that it was a flesh-eater, which, as Owen suggested, may have preyed on the contemporary giant kangaroos or even the still more gigantic diprotodons. Nevertheless, it is believed that Thylacoleo was descended from herbivorous marsupials allied to the phalangers, and, this being so, it is not easy to see why the author assigns it to a family group by itself. This, however, is but a detail.

The marsupials of Australasia, it is pointed out, must have come either from the north-west by way of the Malay Archipelago and Papua, or from the south through an Antarctic connection. Certain objections raised by Prof. Baldwin Spencer against a Malayo-Papuan route are discounted, but the author does not commit himself to any definite opinion as to the probable line of immigration.

As to the date of the immigration, the author, after mentioning that one authority makes it Jurassic, a second Cretaceous, and a third Eocene, inclines to the opinion that it did not take place until the Miocene or middle division of Tertiary time. Although we incline to the view that it was probably. Tertiary, so late an epoch as the Miocene seems to allow a very short period for the evolution of the numerous modern forms and their immediate ancestors.

Later on, it is argued that opossums may be the descendants of Jurassic ancestors, or they may themselves be the original marsupials. Assuming the latter to be the case, it may be asked, was the arboreal marsupial radiation only Tertiary, and are creodonts (inclusive of the South American sparassodonts) and the thylacine developments of an earlier common terrestrial stock related to the still earlier mammal-like reptiles?

Summing up the evidence as to the diffusion of modern marsupials, the author is of opinion that during the Oligocene period there was a radiation of opossums throughout a large portion of the northern hemisphere, and that some of these animals gained an entry into South America, where they may have given rise to the extinct Microbiotheriidæ of Patagonia. Then came the immigration into Australasia, during Miocene or Middle Tertiary time. About the same period occurred the great development of South American marsupials, such as the extinct Abderitidæ and the forerunners (Epanorthidæ) of the modern 